\title{
Use of Business Analytics in Accounting Firms-Taking Deloitte as an Example
}

\author{
Hsin-Yu Chien ${ }^{1}$ \\ ${ }^{1}$ Accounting Department, University of Connecticut, Connecticut, US
}

\begin{abstract}
This paper aims to introduce business analytics strategies that one of the most prominent public accounting firms, Deloitte, has applied to manage hundreds of thousands of clients and discover valuable insights within the organization to increase efficiency and improve risk management. According to Deloitte official website, $76 \%$ of audit committee members within the organization believe that advanced technology should be used more extensively [1]. The insights gained from the data analytics are approved by the most occupied position in the accounting firm, which is the auditors. This paper introduces insight-driven methods used in the company, including Profit model, Network, Structure, Process, Product performance, Product system, Service, Channel, Brand, and Customer engagement. All of these elements can each be integrated into a business analytic approach. Lastly, this paper will provide some limitations associated with the data analysis in the firm.
\end{abstract}

\section{INTRODUCTION}

This paper focuses on the practical use of "Big Data" in Deloitte since it has generated significant business management insights and led companies to reevaluate the efficiency of their daily work. The differences in various aspects of the process between traditional auditing and trending auditing are discussed in the paper. The traditional record-to-report of auditing practices limits the visibility of the data. The new approach not only escalate auditors' efficiency in inputting, accessing, and analyzing client's financial reports, but also keeping the employee in a broader business calendar. Moreover, the Customer Value Model helps to calculate the total value each client brings over his projected lifetime before Deloitte makes contact with its client, every six to twelve months since the company prefers to work with clients with increasing value over time. Customizing its characteristic in detecting fraud inside the company helps Deloitte better manage and examine a large number of clients.

\section{OVERVIEW OF DeloitTE}

Big data plays an intriguing role in making one of the Big Four, Deloitte's success, from financial performance management, advanced forecasting, to fraud and forensics. Deloitte makes the switch from the traditional accounting auditing process into continuous auditing by making the software to do the retroactive and repetitive work. Previously, auditors had to manually input the data to generate monthly, semiannual, or annual reports for the clients, which was inefficient. Ratio, trend, and regression analysis are the basic statistical techniques used in a traditional auditing process. Also, data modeling helps not only efficiency but also enhances transparency between the transactions and information sharing between the employees. Making the data perceivable to the employees helps them to improve their analytical skills as well as decision making ability. The premise to this is that accountants have technical skills to run large sets of data with statistical analysis tool. Therefore, the company should keep making effort in educating the decision makers to be familiar with the models used in the accounting industry.

\section{AdVANCED analytics in Financial SERVICE}

Auditing is a significant part of the accounting since it plays an initial role in analyzing an organization's financial status. As accounting journals get broadened and perplexing, leading auditing can use models to reduce the margin of omissions, errors, or fraud. Deloitte audit methodology recognizes the advances in the management of statistical science and data set. Table 1 shows how transformational applications change the auditing process by comparing the differences between the traditional audits and the leading audits. With the software and the auditor's capability to analyze entire sets of translation rather than a sample, the outliers are more quickly and accurately identified [3]. With the help of big data applied in auditing practice, accountants now move from doing repetitive accounting tasks to creating financial plans and offering insights to their clients. Therefore, the advanced technologies not only help with

$\overline{\text { hsin-yu.chien@uconn.edu }}$ 
the task's efficiency, but also increase the competitiveness between accountants because they offer advice that is more specific to the clients need.

TABLE 1. TRADITIONAL VERSE LEADING AUDITS (SOURCE: THE CPA JOURNAL)

\begin{tabular}{|c|c|c|}
\hline & Traditional Audits & Future Audits \\
\hline Data Type & Quantitative and structured & Unstructured and semi-structured \\
\hline Frequency & Periodic & Continuous \\
\hline Approach & Reactive & Automatic and continuous controls \\
\hline Procedure & Manual and analytical review & Handling exceptions \\
\hline Nature & Time intensive labor & Collaborative \\
\hline Internal & Independent role & Certifier of the auditing system \\
\hline External & Independent role & Models monitors entire population \\
\hline Testing & Humans perform sample testing & Continuous \\
\hline Reporting & Periodic & \\
\hline
\end{tabular}

The use of business analytics also helps clients engage in a Tax Management approach. Deloitte has faced the complexity of the changing tax code. A proper application can track tax rates and calculate possible tax savings by manually inputting some rules. The result of the analysis can be visually presented to its clients in an intelligible format [6].

\section{Enterprise Fraud MANAGement (EFM)}

Anti-Fraud programs created by Deloitte involves various aspects from prevention, detection, to response. Enterprise Fraud Management takes an integrated view of an organization, calculating fraud risks and patterns at an enterprise level. Applying machine learning to business, the Enterprise Fraud Management model can detect abnormal events with specific characteristics associated with fraud in the past, such as intentional omission, manipulation, and misappropriation of funds [4]. Deloitte held its Financial Crime Strategy conference in 2014. It recognized the critical observations relating to their financial crime strategy fraud formulation, including that financial and reputational cost of non-compliance is increasing, and technology is indispensable in targeting potential risk and allowing the company to combat financial crime. Figure 1 shows that most delegates believe that effective analytics delivers value across a range of financial crime processes and helps reduce monetary and relational losses.

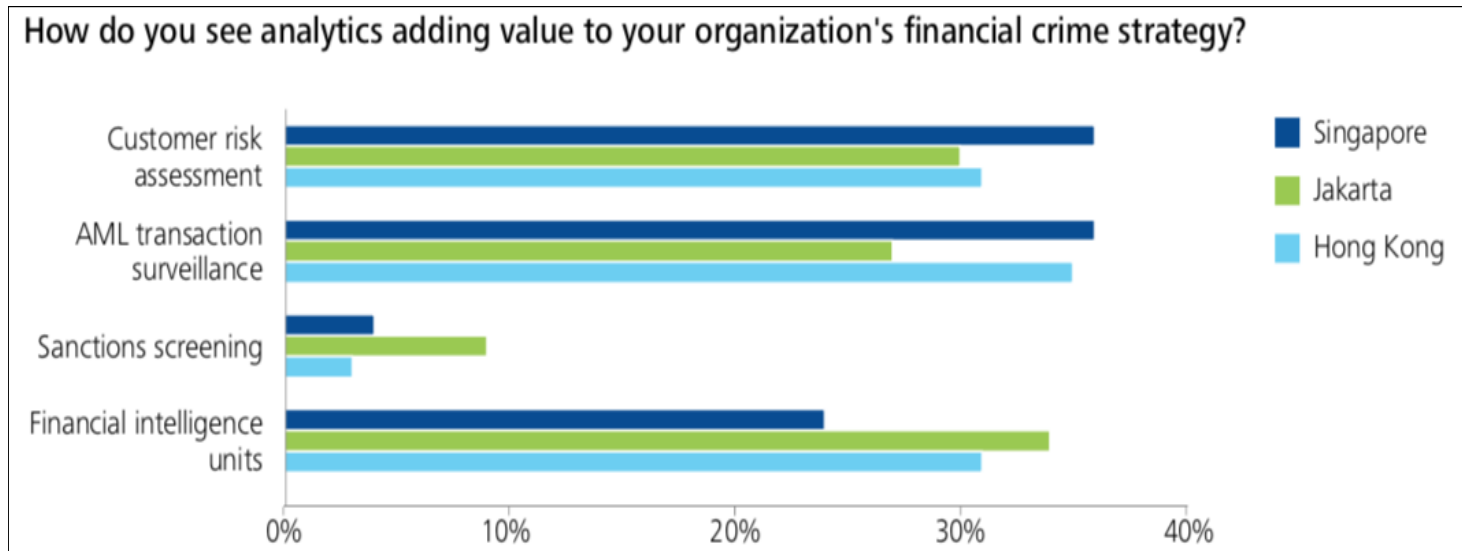

Figure 1. A survey from delegates in three locations (source: Deloitte Financial Crime Strategy)

The classification is used in machine learning group data together by sets of criteria, such as a change in receivable, change in inventory, and change in payment method. Features capture the nature of the business, whether the clients in manufacturing, computer, construction industry. The goal of this model is to distinguish fraudulent transactions from thousands of unorganized ones, and using the model can get a result in a short time. Another model used in detecting fraud is the Forensic Data Analytics. It enables periodic monitoring 
of controls using technologies, and it also investigates fraud by signals from cases and confirmed fraud. It is important for a company to continue improving the measurements because the fraud risk assessment would be more daunting when there is large amount of data sets.

Figure 2 demonstrates that executives at more effective organizations anticipated that fraud incidents were less likely to occur over the next year as compared with organizations with less effective fraud controls. The gap between the difference between two types of company is an improved employee sensitization and the awareness of fraud.

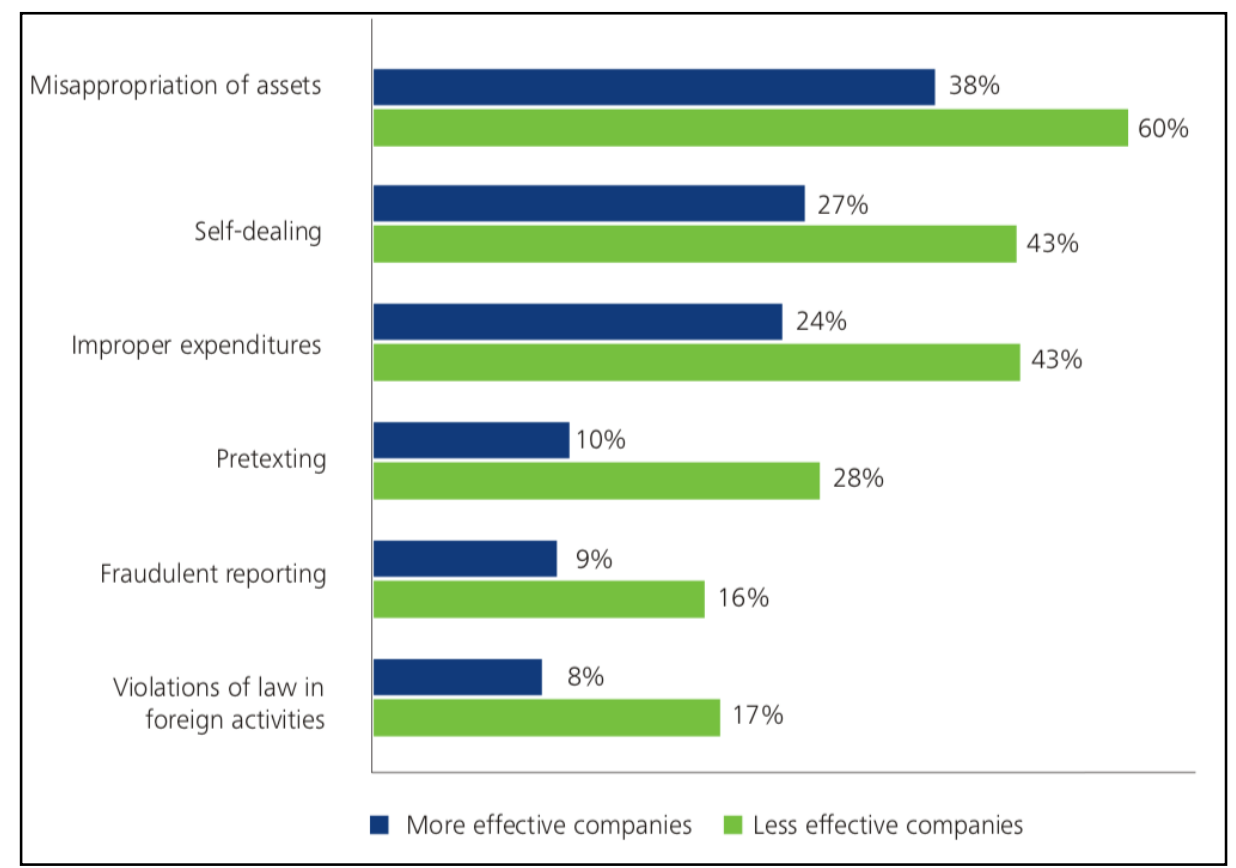

Figure 2. Percent of executive responding to the likelihood of the fraud

\section{Customer Value Measure}

Lack of customer relationships can be harmful to an organization in the long term, especially in the financial service industry like Deloitte, because there are too many competitors in the environment. An organization must measure each client's lifetime value to the business for differentiated treatments, diagnosis, analysis, and understanding of valuable customers. Deloitte separates the customer value into two sides: experience value and business value because the company wants to know how satisfied the customers are and how much the client promotes the company and their cost to serve. There are different approaches that Deloitte developed in understanding their business partner, such as the Next Best Action (NBA) approach which implements a customer-level decision engine which optimizes offers to their clients based on the likelihood to the client's positive response as well as a business priority. The program satisfies both the organization's and the customers' needs. Deloitte also adopts an "Always on marketing" approach that refers to an optimal state where an organization successfully delivers the most relevant message and consistent experience. Pricing, promotion, reliability, and service quality must be retained at a high level of satisfaction to ensure the organization's future growth, and a comprehensive data analysis could perform all of the information for clients in different demographics. Customer lifetime value (CLV) metric predicts the net present value of future profitability for each customer using regression trees with high quality of input. The micro-segmentation model is based on linear algebra and calculates the average for the clients' credit score for a fixed-length period [5]. The metric can be difficult to calculate since there are variety of different formulas depends on how many aspects of a client Deloitte wants to take into consideration in defining a high-value customer.

Figure 3 is an example of a Customer Lifetime Value formula. It is based on the profitability of a company and unique customers count by measuring the retail profit per transaction and sales per unique customer. Thus, CLV addresses the heart of a client's performance in growth and profitability.

Cont.Marg. $\times \frac{\text { Retention rate }}{1+\text { disc rate }- \text { retention rate }}$

Figure 3. Customer lifetime value formula

\section{LimitATIONS AND SOLUTIONS}

Even though business intelligence has helped Deloitte to grow, developing technology has many issues to deal with such as data breaches, high price, difficulty in analysis of various sources, resistance to technology adoption. Since Deloitte has a diverse type of clients, the sensitive information could potentially be breached by accessing a laptop or bypassing network security remotely. Even though Deloitte had done an excellent job 
ensuring the security of its confidential data, using twofactor authentication which involves giving supplementary information such as access code sent by text, or personal information checks before accessing clients' information [2]. Based on figure 3, another issue regarding the application of business analytics is that most executives are uncomfortable using data from the resources either because they simply are not familiar with the techniques, they think the company is not an insightdriven organization or they do not want to take more responsibilities.

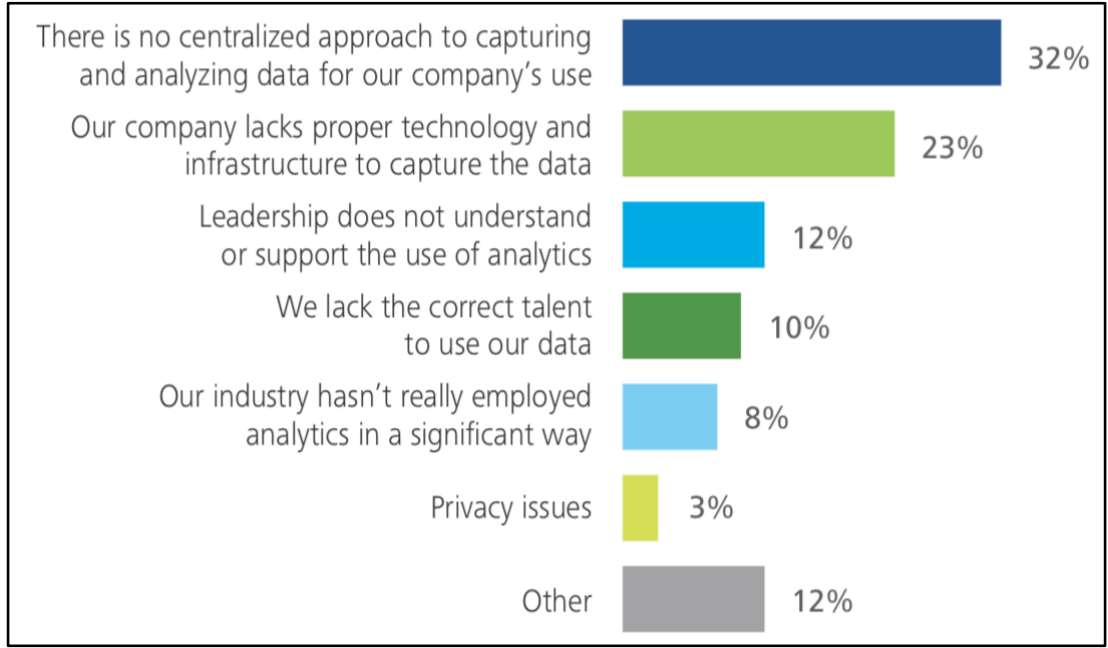

Figure 4. Barriers to Analytics used (source: Deloitte analytics and IBM software)

However, the company can solve this problem by giving incentives in learning new analytics skills, communicating different perspectives on how data can be useful, and upgrading the technology to support the implementation of new analytical tools. This technical transition requires years of training and adjusting. Once the data-driven approach becomes mainstream, managers and employees will understand that analytics can help them make better decisions in improving customer service, identifying business processes, informing marketing, and deriving performance measurement. Since Deloitte has already established a model to examine customer value, it is crucial to develop another model to personalize client engagements. For example, sending text message according to their needs and providing loyalty benefits for retention.

Even though business intelligence has helped Deloitte grow, developing technology has many issues to deal with, such as data breaches, high price, difficulty in the analysis of various sources, and resistance to technology adoption. Since Deloitte has a diverse type of clients, sensitive information could potentially be breached by accessing a laptop or bypassing network security remotely. Even though Deloitte had done an excellent job ensuring the security of its confidential data, using twofactor authentication involves giving supplementary information such as access code sent by text, or personal information checks before accessing clients' information [2]. Based on figure 4, another issue regarding the application of business analytics is that most executives are uncomfortable using data from the resources either because they are not familiar with the techniques, think the company is not an insight-driven organization, or do not want to take more responsibilities.

\section{CONCLUSION}

With the emergence of business analytics, a lot of repetitive work in public accounting firms is replaced by data models. Even though it takes up years in transitioning the entire organization into a data-driven decision-making approach, the impact on the profitability of the company is long-lasting. All the model introduced in this paper, such as The Next Best Action (NBA), Tax Management, Always on marketing, Customer lifetime value, and Enterprise Fraud Management approaches, require different machine learning algorithms to make the accounting information more accurate and analytical. However, this paper does not explain the technical aspect of these algorithms. The information provided in this paper implies that big data plays a huge role in accounting practices. Even though the answer to whether there is going to be changed in current auditing procedures due to big data remains unknown, it is certain for the auditors to develop a thorough understanding of the presentation of big data in financial statements, as well as the integration of big data in detailed audit practice is on its way [7]. Besides, it is also expected that more software will be developed to support more complex transactions. Top accounting firm like Deloitte must integrate more techniques into their business models. Meanwhile, the users have to be aware of the challenges, such as the quality of data, the source of the data, as well as the choice of data.

\section{ACKNOWLEDGEMENT}

I would like to show my deepest gratitude to the accounting professors at the University of Connecticut, who have guided me in completing the research paper. 
Further, I would like to offer my sincere appreciation for the learning opportunities provided by Dr. Stephen Coggeshall from the Department of Data Sciences at the University of Southern California, his useful insights in business analysis models, and my classmates and parents. Without all the enlightening instructions and extraordinary kindness, this research paper could not have been accomplished.

\section{REFERENCES}

1. "Deloitte Analytics Services: Deloitte: Deloitte Analytics." Deloitte, 2020, Retrieved from www2.deloitte.com/global/en/pages/deloitteanalytics/topics/deloitte-analytics-services.html. [Accessed on July 28, 2020]

2. "Deloitte Hit by Data Breach." BBC News, BBC, 25 Sept. 2017, Retrieved from www.bbc.com/news/technology-41385951. [Accessed on July 16, 2020]

3. Tang, Jiali, and Khondkar E. Karim. "Big Data in Business Analytics: Implications for the Audit Profession.” The CPA Journal, 22 June 2017, Retrieved from www.cpajournal.com/2017/06/26/big-data-businessanalytics-implications-audit-profession/. [Accessed on July 20, 2020]

4. "Addressing the Financial Crime Challenge in a Holistic, Effective Way: Forensic: Deloitte Guam: Services, Reports \& Insights.” Deloitte, 9 Feb. 2015, Retrieved from www2.deloitte.com/gu/en/pages/financialadvisory/articles/deloitte-forensic-financialcrime.html. [Accessed on July 16, 2020]

5. Deloitte. "Customer Lifetime Value." Deloitte Czech Republic, Deloitte, 2020, Retrieved from www2.deloitte.com/cz/en/pages/deloitteanalytics/solutions/customer-lifetimevalue.html?fbclid=IwAR10mAOEqaIkb4jETr5As6 TkTBhmrMVKZZxdBJ_OyNv-W3-zD0Rvph1QEjs. [Accessed on July 18, 2020]

6. Earley, Christine E. "Data Analytics in Auditing: Opportunities and Challenges." Business Horizons 58.5 (2015): 493-500.

7. Tang, Jiali, and Khondkar Karim. "BIG DATA IN ACCOUNTING." Internal Auditing32.2 (2017): 2931. 